\title{
Ganglionated plexi as neuromodulation targets for atrial fibrillation
}

Eue-Keun Choi, M.D., Ph.D.; Y Ye Zhao, M.D., ${ }^{b}$ Thomas H. Everett, IV, Ph.D., ${ }^{c}$ Peng-Sheng Chen, M.D. ${ }^{\mathrm{c}}$

${ }^{a}$ Department of Internal Medicine, Seoul National University Hospital, Seoul, Republic of Korea;

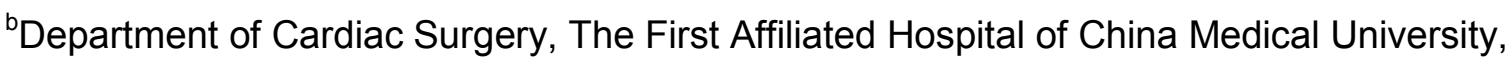
Sheng Yang, China;

${ }^{\mathrm{C}}$ The Krannert Institute of Cardiology and Division of Cardiology, Department of Medicine, Indiana University School of Medicine, Indianapolis, Indiana

Short title: GP ablation for AF

Corresponding author:

Peng-Sheng Chen, MD

Indiana University School of Medicine

1800 N Capitol Ave, E475, Indianapolis, IN 46202

E-mail chenpp@iu.edu

This study was supported in part by a grant no 0620160680 from the SNUH Research Fund, and a grant from the National Research Foundation (NRF) of Korea, funded by the Ministry of Education, Science and Technology (2014R1A1A2A16055218) (Dr Choi), NIH grant R42DA043391 and the Charles Fisch Cardiovascular Research Award endowed by Dr Suzanne B. Knoebel of the Krannert Institute of Cardiology (Dr Everett), NIH Grants R56HL071140-13A1, P01HL78931, R01HL71140, a Medtronic-Zipes Endowment and the

This is the author's manuscript of the article published in final edited form as:

Choi, E.-K., Zhao, Y., Everett, T. H. and Chen, P.-S. (), Ganglionated plexi as neuromodulation targets for atrial fibrillation. J Cardiovasc Electrophysiol. Accepted Author Manuscript. http://dx.doi.org/10.1111/jce.13319 
Indiana University Health-Indiana University School of Medicine Strategic Research Initiative (Dr Chen).

\section{Abstract}

The autonomic nervous system plays an important role in the genesis of atrial fibrillation and is one of the candidate targets for atrial fibrillation therapy. This review focuses on the role of the autonomic nervous system in atrial fibrillation development and discusses the results of the ganglionated plexi catheter and surgical ablation in preclinical and clinical studies. The heart is innervated by the extrinsic and intrinsic autonomic nervous systems. The intrinsic autonomic nervous system consists of multiple ganglionated plexi and axons, which innervate the neighboring atrial myocardium and control their electrophysiological properties. Abnormal autonomic innervation has been observed in an animal model of atrial fibrillation and in humans. Direct recordings of autonomic nerve activity in canine models showed that atrial tachyarrhythmia episodes were invariably preceded by intrinsic cardiac autonomic nerve activity, thus supporting the importance of intrinsic cardiac autonomic nerve activity as the triggers for atrial tachyarrhythmia. Targeting ganglionated plexi with catheter ablation improves the outcomes of paroxysmal atrial fibrillation ablation in addition to pulmonary vein antrum isolation. Ablation of ganglionated plexi alone without pulmonary vein isolation is also useful in controlling paroxysmal atrial fibrillation in some patients. However, surgical ganglionated plexi ablation in patients with a large left atrium, persistent atrial fibrillation and/or a history of prior catheter ablation does not result in additional benefits. These different outcomes suggest that ganglionated plexi ablation is effective in managing patients

This article is protected by copyright. All rights reserved. 
with paroxysmal atrial fibrillation, but its effects in patients with persistent atrial fibrillation and advanced atrial diseases might be limited.

Keywords: atrial fibrillation, ganglionated plexi, autonomic nervous system, catheter ablation, surgical ablation, vagus

\section{Introduction}

Atrial fibrillation $(\mathrm{AF})$ is the most common type of sustained arrhythmia in adults. It can cause cardiovascular complications such as ischemic stroke, systemic embolism, heart failure, and death. The estimated prevalence in the United States is approximately 5.2 million, and it is expected to increase up to 12.1 million by the year of $2030 .{ }^{1}$ Although the prevalence and incidence of AF have been lower in Asian countries than in Western countries, its rate is rapidly increasing. ${ }^{2}$ Catheter or surgical ablation is one of the most important strategies for treating AF. It disconnects between the triggers within the pulmonary vein (PV) and the left atrium (LA) or eliminates the non-PV foci. In addition, ablation of the ganglionated plexi (GP) during pulmonary vein antrum isolation (PVAl) could suppress the vagal response and contribute to the effectiveness of AF ablation. ${ }^{3}$ In this review, we focus on the role of the autonomic nervous system (ANS) in AF development and discuss the recent results of catheter and surgical ablation of the GP in managing patients with AF.

\section{Anatomy of the cardiac autonomic nervous system}

This article is protected by copyright. All rights reserved. 
The heart is innervated by the extrinsic and intrinsic ANS and contains more than 14,000 neurons. ${ }^{4}$ The extrinsic ANS consists of both sympathetic and parasympathetic components that originates from vagal nerves and the paravertebral sympathetic ganglia, such as the stellate (cervicothoracic) ganglion. The intrinsic ANS is also very complex. GP are positioned mostly within the epicardial fat pad, and are composed of various ganglia and interconnecting axons. Ganglia contain 200 to 1000 neurons that innervate neighboring cardiac structures, and connect with sympathetic and parasympathetic nerve fibers from the extrinsic ANS. ${ }^{4}$ Most GP are located near the large vessels and posterior surface of the atrium, and $50 \%$ of all cardiac ganglia are located near the heart hilum, especially on the dorsal and dorsolateral surfaces of the LA. Sympathetic nerve activation could induce arrhythmias by enhancing calcium entry, storage, and release in the heart. ${ }^{5}$ Parasympathetic nerve activation could reduce the atrial effective refractory period ${ }^{6}$ and promote development of late phase 3 early after depolarization-induced triggered activity in the atria and the PVs. ${ }^{7}$ ${ }^{8}$ The sinus node is primarily innervated by the right atrial GP, whereas the atrioventricular (AV) node is innervated by the inferior vena cava-inferior atrial GP (also known as the inferior right or right inferior GP). The four major GP located near the antrum of the PV are as follows: superior left GP (located on the roof of the LA, near the medial side of the left superior PV); anterior right GP (located anterior to the right superior PV); inferior left GP and inferior right GP (located at the inferior aspect of the posterior LA wall, just below the left and right inferior PV). ${ }^{9} \mathrm{GP}$ are connected with each other by interconnecting neurons and create an extensive and complicated epicardial neural network. The function of GP is to modulate the autonomic interactions between the extrinsic and intrinsic ANS, which affects the sinus rate, $\mathrm{AV}$ conduction, refractoriness, and inducibility of $\mathrm{AF} .{ }^{10}$ Most autonomic nerves are

This article is protected by copyright. All rights reserved. 
located within $5 \mathrm{~mm}$ of the LA and PV junction and in the anterosuperior segments of the superior veins and inferior segments of both inferior veins. ${ }^{11}$ Adrenergic and cholinergic nerves are highly co-localized within these areas; therefore, selective ablation of either adrenergic nerves or cholinergic nerves is challenging. Considering the close proximity of the autonomic nerves with the commonly ablated lesion set for circumferential PVAI, the procedure could result in unintentional autonomic denervation within the LA-PV junction.

\section{Direct recording of the autonomic nervous system and atrial tachyarrhythmia}

The role of ANS on cardiac arrhythmogenesis was evaluated by direct recording of autonomic nerve activity in ambulatory animals ${ }^{12,13}$ and in humans. ${ }^{14,15}$ There was circadian variation in the sympathetic outflow from the canine stellate ganglia. Simultaneous sympathovagal discharges often precede paroxysmal atrial tachycardia (AT) events. ${ }^{16}$ To further analyze the relationship between cardiac autonomic nerve activity and atrial tachyarrhythmia, intermittent rapid atrial pacing was performed to increase the number of episodes of spontaneous atrial tachyarrhythmia before developing persistent AF. ${ }^{17}$ After cryoablation of the stellate ganglion and the superior cardiac branch of the vagus nerve, paroxysmal AF and AT were not observed, suggesting a causal relationship between ANS and atrial tachyarrhythmia. However, cryoablation could delay, but not prevent, the development of sustained AF by rapid atrial pacing, indicating that there could be factors other than nerve activity that determined AF maintenance. To determine the role of the intrinsic ANS, we directly recorded both extrinsic and intrinsic autonomic nerve activity in an ambulatory canine model (Figure 1). ${ }^{18}$ Multiple episodes of paroxysmal AT and AF were

This article is protected by copyright. All rights reserved. 
observed before sustained AF developed. Atrial tachyarrhythmia episodes were invariably preceded by intrinsic cardiac nerve activity, thus supporting the importance of GP for triggering atrial tachyarrhythmia. The development of technology that allows investigators to simultaneously and non-invasively record human skin sympathetic nerve activity, ${ }^{19}$ has shown that increased skin and intrinsic cardiac nerve activities were associated with the development of paroxysmal atrial tachyarrhythmia episodes in humans. ${ }^{14,15}$ These findings are consistent with those observed in canine models.

The correlation between sympathetic and vagal nerve activity is important in the maintenance of $A F{ }^{20}$ In a majority of dogs, stellate ganglion nerve activity (SGNA) and vagal nerve activity (VNA) showed a nonlinear or L-shaped relationship, with a low correlation coefficient. However, in a minority of dogs, SGNA and VNA showed an excellent linear correlation, indicating frequent synchronous firing between the two. The latter group of dogs had more paroxysmal atrial tachyarrhythmia episodes at baseline and shorter pacing duration to induce sustained AF compared with the former group of dogs. These results could partially explain the inter-individual variations of susceptibility for persistent AF.

\section{Neuromodulation of ganglionated plexi}

\subsection{Drugs}

Carvedilol, a non-selective beta-blocker, suppresses SGNA, VNA and GP nerve activity. ${ }^{21}$ Carvedilol withdrawal may lead to significant rebound of the nerve activity, suggesting the chance of adverse events in those who have neural remodeling when the beta-blocker is

This article is protected by copyright. All rights reserved. 
suddenly discontinued. However, nadolol did not significantly suppress SGNA in ambulatory dogs. ${ }^{13}$ Lidocaine injection into the GP suppresses AF inducibility. ${ }^{22}$ Oh et al. reported the short-term to mid-term effects of botulinum toxin, a cholinergic neurotransmission blocker, on AF inducibility in a canine model. ${ }^{23}$ Botulinum toxin injection in two fat pads suppressed AF inducibility at 1 week, but this disappeared at 2 weeks and 3 weeks. In human randomized clinical trials, however, botulinum toxin injected in the epicardial fat pads during cardiac surgery not only suppressed postoperative AF but also reduced the incidence of $A F$ for at least 1 -year. ${ }^{24}$ The prolonged benefit suggest that botulinum might induce GP remodeling.

\subsection{Radiofrequency catheter ablation}

Pappone et al. reported that abolition of the vagal response during circumferential PVAI could be achieved in one-third of patients, with heart rate variability attenuation up to 3months, and resulted in less AF recurrence at 12 months ${ }^{25}$ This study supports the idea that GP could be used as a target during AF ablation. GP ablation could be performed using two methods: the functional approach, which uses selective high-frequency stimulation to find the location of the GP, or the anatomical approach, which uses 3D electroanatomical mapping to identify the presumed 4 major GPs. High frequency stimulation could induce vagal responses, including AV block (>2 seconds), hypotension or prolongation of the R-R interval by more than $50 \%$ during $A F .{ }^{26}$ These responses could be used to guide GP ablation. Anatomic GP ablation is simpler than the functional approach using high frequency stimulation, but there are several limitations. The GP border cannot be clearly defined and the efficacy of ablation is judged by only by local electrogram amplitude reduction. There is

This article is protected by copyright. All rights reserved. 
the possibility of inter-individual differences in the presumed location of GP. Nevertheless, selective GP ablation is associated with a higher recurrence of AF compared with anatomic GP ablation for patients with paroxysmal $\mathrm{AF}^{27}$

The Table 1 summarizes the clinical studies showing the feasibility and efficacy of GP ablation. The comparison between GP ablation only and PVAI was reported in two small studies and in one meta-analysis using those two studies. ${ }^{28-30}$ Both studies used the anatomical GP ablation technique. Patients who underwent GP ablation alone showed higher early recurrence rates compared with those who underwent ablation with PVAI alone. The study population was small, but the inferior results of GP ablation alone were consistent. Three studies compared the efficacy of PVAI plus additional GP ablation versus PVAI alone. ${ }^{31-33}$ Scherlag et al. identified GP using high frequency stimulation and the vagal response. ${ }^{33}$ Ablation at those areas abolished the vagal response. PVAI with additional GP ablation resulted in better AF-free survival compared with PVAl alone (91 vs. $71 \%$ ). Katritsis et al. compared anatomic GP ablation in addition to PVAI to PVAl alone in paroxysmal AF patients $(n=67) .{ }^{31}$ Combined GP ablation and PVAl resulted in better AF-free survival compared with PVAl alone. The study was extended to compare the efficacy of ablation among three groups of patients with paroxysmal AF ( $n=242)$ : PVAl alone vs. GP ablation alone vs. PVAI with GP ablation. ${ }^{32}$ Additional anatomic GP ablation with conventional PVAI resulted in better AF-free and AT-free survival compared with either PVI or GP ablation alone $(74 \%$ vs. $56 \%$ vs. $48 \%$, respectively; $p=0.004$ by log-rank test). However, it is interesting to note that GP ablation alone was associated with a $48 \%$ success rate, supporting the importance of GP in the generation of paroxysmal AF. Additional GP ablation showed beneficial effects during repeated procedure of PVAI in patients who had

This article is protected by copyright. All rights reserved. 
paroxysmal AF recurrence after PVAI. ${ }^{34}$ Several observational GP ablation studies without a control group reported variable AF-free survival rates of $38-80 \%{ }^{9,}{ }^{35-38}$ One study performed GP ablation alone exclusively for patients with long-standing persistent AF. ${ }^{36}$ Although the AF-free survival rate was lower (38\%) after GP ablation alone, subsequent repeat PVAI increased the rate to $60 \%$, suggesting partial efficacy of GP ablation alone for this population. A limitation of these studies is that GP are primarily located near the LA-PV junction and that it is difficult to selectively ablate the GP without damaging the nearby myocardium. Therefore, attempted GP ablation could result in a wider circumferential ablation of the LA-PV junction. The latter effects might account for the better outcomes of ablation.

\subsection{Surgical ablation}

The Cox-Maze III procedure is an effective surgical method for treating AF, but it has not been accepted as a stand-alone treatment due to its invasiveness and complexity. ${ }^{39}$ Recently, minimally invasive surgery was reported as a reasonable option for patients with lone AF based on the benefit of a smaller incision and reduced complications related to cardiopulmonary bypass compared with Cox-Maze surgery. This approach could ablate GP located in the epicardium more effectively than endocardial catheter ablation. In a canine model involving rapid atrial pacing-induced AF, ablation was performed at the superior left GP (SLGP) and the Ligament of Marshall (LOM), and the spontaneous occurrence of paroxysmal atrial tachyarrhythmia was eliminated. ${ }^{40}$ SLGP/LOM ablation also induced cell death in stellate ganglion, which could be due to the dying back degeneration after axonal

This article is protected by copyright. All rights reserved. 
damage. An important physiological consequence is the dramatically reduced heart rate responses to SGNA both during sinus rhythm and during AF (Figure 2). The latter findings suggest that in addition to eliminating the intrinsic cardiac nerve activity, surgical removal of the GPs can also reduce the effects of extrinsic cardiac ANS on the heart.

GP ablation during minimally invasive surgery for AF did not show beneficial effects in preventing AF recurrence. ${ }^{41}$ Studies performing GP ablation reported lower 12-month AFfree survival rates than those without GP ablation. However, there are several limitations to concluding whether GP ablation during minimally invasive surgery had any role in AF prevention because the protocol of GP ablation was not standardized, the number of patients included in those studies was small, and the follow-up duration was relatively short. Recently, Atrial Fibrillation Ablation and Autonomic Modulation via Thoracoscopic Surgery (AFACT) trial tested the efficacy of additional GP ablation during thoracoscopic AF surgery with a randomized controlled study design. ${ }^{42}$ All patients with persistent AF underwent thoracoscopic PV isolation of additional linear lesions (Dallas lesion set). Two-hundred forty patients were randomized to the additional GP ablation group (GP group) or no additional ablation group (control group). Four major GP were localized using anatomic landmarks and high frequency stimulation. GP ablation eliminated the vagal responses completely, whereas $87 \%$ in control group still exhibited the vagal responses. The GP group did not show a statistically significant difference in AF recurrence compared to the control group. However, that group of patients had more events of major bleeding and sinus node dysfunction than patients without GP ablation. Because previous randomized studies using catheter based techniques showed GP ablation is beneficial in AF control, the negative results of AFACT requires some discussion. One possible reason is that Katritsis et al. recruited patients with

This article is protected by copyright. All rights reserved. 
paroxysmal AF and relatively small LA (size $<50 \mathrm{~mm}$ ). All patients with serious comorbidity and previous ablation were excluded. In contrast, most patients in AFACT study had bigger LA, persistent AF or previous ablation with recurrence. Only 26 patients (11\%) had normal LA, and no persistent AF or previous ablation. The AFACT results were in fact similar to that observed in preclinical studies using canine models. In the latter studies, cryoablation of the stellate ganglion, superior cardiac branch of the vagal nerve, epicardial surgical ablation of the GP and vagal nerve stimulation all help reduce or eliminate paroxysmal atrial tachyarrhythmias. However, after prolonged pacing, all dogs eventually went into sustained AF. ${ }^{17,20,40}$ A second difference of these two studies was the duration of follow-up. The AFACT followed up their patients for only 1 year by clinical visits, electrocardiogram and 24hour Holter monitoring every 3 months. In comparison, Katritsis et al. followed up the patient monthly, and half of the patients had the implantable loop recorder.

\section{Limitations of ganglionated plexi ablation}

Catheter or surgical GP ablation could damage various nerve structures, including nerves proximal to the GP, the GP itself, or nerves distal to the GP. In addition, ablation could also damage the myocardium and other non-neuronal structures, leading to the release of neurotrophic factors that promote nerve sprouting. ${ }^{43,44}$ The nerve sprouting could start as early as 2 hours after injury, and might persist for over 1 month. The patterns of reinnervation could be highly heterogeneous, leading to proarrhythmia. A previous study showed that partial vagal denervation could facilitate rather than prevent vagally mediated AF by increasing the heterogeneity of refractoriness within the atria. ${ }^{45}$ Mid-term effects ( 8

This article is protected by copyright. All rights reserved. 
weeks) of epicardial GP ablation without PVAI showed that it could be proarrhythmic due to the decreased atrial effective refractory period and hyper-reinnervation involving both sympathetic and parasympathetic nerves. ${ }^{46}$ Additional GP ablation could create a new substrate for the macro-reentry circuit, which could increase the risk of AT. The AFACT trial also reported that the GP ablation group more frequently showed AT (as opposed to AF) as a clinical recurrence. ${ }^{42}$ Surgical GP ablation significantly reduces atrial vagal innervation, but early reinnervation at 4 weeks was suspected and could explain the nonsustained effect of surgical GP ablation. ${ }^{47}$ In an animal model, the effect of GP ablation on AF inducibility disappeared after 4 weeks. ${ }^{48}$ Finally, the methods of follow-up differed significantly from study to study, making it impossible to compare the absolute success rates among studies.

\section{Conclusion}

GP comprise an important structure that invariably triggers AF. Targeting GP with catheter ablation resulted in better outcomes when combined with conventional PVAI . It is less effective than PVAI when GP ablation was performed alone. While GP ablation seems to have added benefit to PVAl in patients with paroxysmal AF, surgical GP ablation in patients with persistent $\mathrm{AF}$, large LA and previous catheter ablation did not result in additional benefits at one year. There are still many questions regarding how to achieve complete GP ablation without partial denervation, the best targets and methods for catheter-based GP ablation, how to improve the results of surgical GP ablation, how to prevent reinnervation and end-organ hypersensitivity and how to select patients for GP ablation. It is clear that

This article is protected by copyright. All rights reserved. 
more research of this field and novel technologies and strategies are needed before GP ablation can be used effectively in managing patients with AF.

Disclosures: None

\section{Reference}

[1] Colilla S, Crow A, Petkun W, Singer DE, Simon T, Liu X: Estimates of current and future incidence and prevalence of atrial fibrillation in the U.S. adult population. Am J Cardiol $2013 ; 112: 1142-1147$

[2] Lee SR, Choi EK, Han KD, Cha MJ, Oh S: Trends in the incidence and prevalence of atrial fibrillation and estimated thromboembolic risk using the CHA2DS2-VASc score in the entire Korean population. Int J Cardiol 2017; 236:226-231.

[3] Lemola K, Chartier D, Yeh YH, Dubuc M, Cartier R, Armour A, Ting M, Sakabe M, Shiroshita-Takeshita A, Comtois $\mathrm{P}$, Nattel S: Pulmonary vein region ablation in experimental vagal atrial fibrillation: role of pulmonary veins versus autonomic ganglia. Circulation 2008; 117:470-477.

[4] Armour JA, Murphy DA, Yuan BX, Macdonald S, Hopkins DA: Gross and microscopic anatomy of the human intrinsic cardiac nervous system. AnatRec 1997; 247:289-298.

This article is protected by copyright. All rights reserved. 
[5] Chen PS, Chen LS, Fishbein MC, Lin SF, Nattel S: Role of the autonomic nervous system in atrial fibrillation: pathophysiology and therapy. Circulation research 2014; 114:1500-1515.

[6] Zipes DP, DeJoseph RL, Rothbaum DA: Unusual properties of accessory pathways. Circulation 1974; XLIX:1200-1211.

[7] Burashnikov A, Antzelevitch C: Reinduction of atrial fibrillation immediately after termination of the arrhythmia is mediated by late phase 3 early afterdepolarization-induced triggered activity. Circulation 2003; 107:2355-2360.

[8] Patterson E, Jackman WM, Beckman KJ, Lazzara R, Lockwood D, Scherlag BJ, Wu R, Po S: Spontaneous pulmonary vein firing in man: relationship to tachycardia-pause early afterdepolarizations and triggered arrhythmia in canine pulmonary veins in vitro. JCardiovascElectrophysiol 2007; 18:1067-1075.

[9] Po SS, Nakagawa H, Jackman WM: Localization of left atrial ganglionated plexi in patients with atrial fibrillation. J Cardiovasc Electrophysiol 2009; 20:1186-1189.

[10] Hou Y, Scherlag BJ, Lin J, Zhang Y, Lu Z, Truong K, Patterson E, Lazzara R, Jackman WM, Po SS: Ganglionated plexi modulate extrinsic cardiac autonomic nerve input: effects on sinus rate, atrioventricular conduction, refractoriness, and inducibility of atrial fibrillation. JAmCollCardiol 2007; 50:61-68.

[11] Tan AY, Li H, Wachsmann-Hogiu S, Chen LS, Chen PS, Fishbein MC: Autonomic innervation and segmental muscular disconnections at the human pulmonary vein-atrial junction: implications for catheter ablation of atrial-pulmonary vein junction. Journal of the American College of Cardiology 2006; 48:132-143.

This article is protected by copyright. All rights reserved. 
[12] Barrett CJ, Ramchandra R, Guild SJ, Lala A, Budgett DM, Malpas SC: What sets the long-term level of renal sympathetic nerve activity: a role for angiotensin II and baroreflexes? CircRes 2003; 92:1330-1336.

[13] Jung BC, Dave AS, Tan AY, Gholmieh G, Zhou S, wang DC, Akingba G, Fishbein GA, Montemagno C, Lin SF, Chen LS, Chen PS: Circadian variations of stellate ganglion nerve activity in ambulatory dogs. Heart Rhythm 2006; 3:78-85.

[14] Uradu A, Wan J, Doytchinova A, Wright KC, Lin AY, Chen LS, Shen C, Lin SF, Everett Tt, Chen PS: Skin Sympathetic Nerve Activity Precedes the Onset and Termination of Paroxysmal Atrial Tachycardia and Fibrillation. Heart Rhythm 2017; 14:964-971.

[15] Shen MJ, Coffey AC, Straka S, Adams DE, Wagner DB, Kovacs RJ, Clark M, Shen C, Chen LS, Everett THt, Lin SF, Chen PS: Simultaneous Recordings of Intrinsic Cardiac Nerve Activities and Skin Sympathetic Nerve Activities From Human Patients During the Postoperative Period. Heart Rhythm 2017.

[16] Ogawa M, Zhou S, Tan AY, Song J, Gholmieh G, Fishbein MC, Luo H, Siegel RJ, Karagueuzian HS, Chen LS, Lin SF, Chen PS: Left stellate ganglion and vagal nerve activity and cardiac arrhythmias in ambulatory dogs with pacing-induced congestive heart failure. $\mathrm{J}$ Am Coll Cardiol 2007; 50:335-343.

[17] Tan AY, Zhou S, Ogawa M, Song J, Chu M, Li H, Fishbein MC, Lin SF, Chen LS, Chen PS: Neural mechanisms of paroxysmal atrial fibrillation and paroxysmal atrial tachycardia in ambulatory canines. Circulation 2008; 118:916-925.

[18] Choi E-K, Shen MJ, Han S, Kim D, Hwang S, Sayfo S, Piccirillo G, Frick K, Fishbein MC, Hwang C, Lin S-F, Chen P-S: Intrinsic cardiac nerve activity and paroxysmal atrial tachyarrhythmia in ambulatory dogs. Circulation 2010; 121:2615-2623.

This article is protected by copyright. All rights reserved. 
[19] Doytchinova A, J. H, Y. Y, Lin H, Yin D, Adams D, S. S, K. W, K. S, Wagner D, Shen C, C. S, Salanova V, Meshberger C, Kincaid J, Coffey AC, Wu G, Li Y, Kovacs RJ, everett IV TH, Victor RG, Cha YM, Lin S-F, Chen P-S: Simultaneous non-Invasive Recording of skin sympathetic nerve activity and electrocardiogram. Heart Rhythm 2017; 14:25-33.

[20] Shen MJ, Choi EK, Tan AY, Han S, Shinohara T, Maruyama M, Chen LS, Shen C, Hwang C, Lin SF, Chen PS: Patterns of baseline autonomic nerve activity and the development of pacing-induced sustained atrial fibrillation. Heart Rhythm 2011; 8:583-589. [21] Choi EK, Shen MJ, Lin SF, Chen PS, Oh S: Effects of carvedilol on cardiac autonomic nerve activities during sinus rhythm and atrial fibrillation in ambulatory dogs. Europace 2014; 16:1083-1091.

[22] Scherlag BJ, Yamanashi W, Patel U, Lazzara R, Jackman WM: Autonomically induced conversion of pulmonary vein focal firing into atrial fibrillation. JAmCollCardiol 2005; 45:1878-1886.

[23] Oh S, Choi EK, Zhang Y, Mazgalev TN: Botulinum toxin injection in epicardial autonomic ganglia temporarily suppresses vagally mediated atrial fibrillation. Circ Arrhythm Electrophysiol 2011; 4:560-565.

[24] Pokushalov E, Kozlov B, Romanov A, Strelnikov A, Bayramova S, Sergeevichev D, Bogachev-Prokophiev A, Zheleznev S, Shipulin V, Lomivorotov VV, Karaskov A, Po SS, Steinberg JS: Long-Term Suppression of Atrial Fibrillation by Botulinum Toxin Injection Into Epicardial Fat Pads in Patients Undergoing Cardiac Surgery: One-Year Follow-Up of a Randomized Pilot Study. Circ Arrhythm Electrophysiol 2015; 8:1334-1341.

[25] Pappone C, Oral H, Santinelli V, Vicedomini G, Lang CC, Manguso F, Torracca L, Benussi S, Alfieri O, Hong R, Lau W, Hirata K, Shikuma N, Hall B, Morady F: Atrio-

This article is protected by copyright. All rights reserved. 
esophageal fistula as a complication of percutaneous transcatheter ablation of atrial fibrillation. Circulation 2004; 109:2724-2726.

[26] Lemery R: How to perform ablation of the parasympathetic ganglia of the left atrium. Heart Rhythm 2006; 3:1237-1239.

[27] Pokushalov E, Romanov A, Shugayev P, Artyomenko S, Shirokova N, Turov A, Katritsis DG: Selective ganglionated plexi ablation for paroxysmal atrial fibrillation. Heart Rhythm 2009; 6:1257-1264.

[28] Katritsis D, Giazitzoglou E, Sougiannis D, Goumas N, Paxinos G, Camm AJ: Anatomic approach for ganglionic plexi ablation in patients with paroxysmal atrial fibrillation. Am J Cardiol 2008; 102:330-334.

[29] Mikhaylov E, Kanidieva A, Sviridova N, Abramov M, Gureev S, Szili-Torok T, Lebedev D: Outcome of anatomic ganglionated plexi ablation to treat paroxysmal atrial fibrillation: a 3-year follow-up study. Europace 2011; 13:362-370.

[30] Zhou Q, Hou Y, Yang S: A meta-analysis of the comparative efficacy of ablation for atrial fibrillation with and without ablation of the ganglionated plexi. Pacing Clin Electrophysiol 2011; 34:1687-1694.

[31] Katritsis DG, Giazitzoglou E, Zografos T, Pokushalov E, Po SS, Camm AJ: Rapid Pulmonary Vein Isolation Combined with Autonomic Ganglia Modification: A Randomized Study. Heart Rhythm 2011; 8:672-678.

[32] Katritsis DG, Pokushalov E, Romanov A, Giazitzoglou E, Siontis GC, Po SS, Camm AJ, loannidis JP: Autonomic denervation added to pulmonary vein isolation for paroxysmal atrial fibrillation: a randomized clinical trial. J Am Coll Cardiol 2013; 62:2318-2325.

This article is protected by copyright. All rights reserved. 
[33] Scherlag BJ, Nakagawa H, Jackman WM, Yamanashi WS, Patterson E, Po S, Lazzara R: Electrical stimulation to identify neural elements on the heart: their role in atrial fibrillation. JIntervCard Electrophysiol 2005; 13 Suppl 1:37-42.

[34] Xu FQ, Yu RH, Guo JJ, Bai R, Liu N, An YI, Guo XY, Tang RB, Long DY, Sang CH, Du X, Dong JZ, Ma CS: Catheter Ablation of Recurrent Paroxysmal Atrial Fibrillation: Is GapClosure Combining Ganglionated Plexi Ablation More Effective? Pacing Clin Electrophysiol 2017; 40:672-682.

[35] Scanavacca M, Pisani CF, Hachul D, Lara S, Hardy C, Darrieux F, Trombetta I, Negrao CE, Sosa E: Selective atrial vagal denervation guided by evoked vagal reflex to treat patients with paroxysmal atrial fibrillation. Circulation 2006; 114:876-885.

[36] Pokushalov E, Romanov A, Artyomenko S, Turov A, Shugayev P, Shirokova N, Katritsis DG: Ganglionated plexi ablation for longstanding persistent atrial fibrillation. Europace 2010; 12:342-346.

[37] Pokushalov E, Romanov A, Artyomenko S, Turov A, Shirokova N, Katritsis DG: Left atrial ablation at the anatomic areas of ganglionated plexi for paroxysmal atrial fibrillation. Pacing Clin Electrophysiol 2010; 33:1231-1238.

[38] Pokushalov E, Romanov A, Artyomenko S, Shirokova N, Turov A, Karaskov A, Katritsis DG, Po SS: Ganglionated plexi ablation directed by high-frequency stimulation and complex fractionated atrial electrograms for paroxysmal atrial fibrillation. Pacing Clin Electrophysiol 2012; 35:776-784.

[39] Prasad SM, Maniar HS, Camillo CJ, Schuessler RB, Boineau JP, Sundt TM, 3rd, Cox JL, Damiano RJ, Jr.: The Cox maze III procedure for atrial fibrillation: long-term efficacy

This article is protected by copyright. All rights reserved. 
in patients undergoing lone versus concomitant procedures. The Journal of thoracic and cardiovascular surgery 2003; 126:1822-1828.

[40] Zhao Y, Jiang Z, Tsai WC, Yuan Y, Chinda K, Choi EK, Fishbein MC, Lin SF, Chen PS, Everett THt: Ganglionated plexi and ligament of Marshall ablation reduces atrial vulnerability and causes stellate ganglion remodeling in ambulatory dogs. Heart Rhythm 2016; 13:2083-2090.

[41] La Meir M, Gelsomino S, Luca F, Pison L, Colella A, Lorusso R, Crudeli E, Gensini GF, Crijns HG, Maessen J: Minimal invasive surgery for atrial fibrillation: an updated review. Europace 2013; 15:170-182.

[42] Driessen AH, Berger WR, Krul SP, van den Berg NW, Neefs J, Piersma FR, Chan Pin Yin DR, de Jong JS, van Boven WP, de Groot JR: Ganglion Plexus Ablation in Advanced Atrial Fibrillation: The AFACT Study. J Am Coll Cardiol 2016; 68:1155-1165. [43] okuyama Y, Pak HN, Miyauchi Y, liu YB, Chou CC, Hayashi H, Fu KJ, Kerwin WF, Kar S, Karagueuzian HS, Fishbein MC, Chen PS, Lan LS: Sympathetic nerve sprouting induced by radiofrequency catheter ablation in dogs. Heart Rhythm 2005; 1:712-717.

[44] Zhou S, Chen LS, Miyauchi Y, Miyauchi M, Kar S, Kangavari S, Fishbein MC, Sharifi B, Chen PS: Mechanisms of cardiac nerve sprouting after myocardial infarction in dogs. Circ Res 2004; 95:76-83.

[45] Hirose M, Leatmanoratn Z, Laurita KR, Carlson MD: Partial vagal denervation increases vulnerability to vagally induced atrial fibrillation. JCardiovascElectrophysiol 2002; 13:1272-1279.

This article is protected by copyright. All rights reserved. 
[46] Mao J, Yin X, Zhang Y, Yan Q, Dong J, Ma C, Liu X: Ablation of epicardial ganglionated plexi increases atrial vulnerability to arrhythmias in dogs. Circ Arrhythm Electrophysiol 2014; 7:711-717.

[47] Sakamoto S, Schuessler RB, Lee AM, Aziz A, Lall SC, Damiano RJ, Jr.: Vagal denervation and reinnervation after ablation of ganglionated plexi. The Journal of thoracic and cardiovascular surgery $2010 ; 139: 444-452$.

[48] Oh S, Zhang Y, Bibevski S, Marrouche NF, Natale A, Mazgalev TN: Vagal denervation and atrial fibrillation inducibility: epicardial fat pad ablation does not have longterm effects. Heart Rhythm 2006; 3:701-708.

\section{Figure Legend}

Figure 1. Autonomic nerve activity and paroxysmal AF in a canine model. A shows the anatomical location of the Ligament of Marshall (LOM) and superior left ganglionated plexi (SLGP). The LOM originates from coronary sinus and connects to left superior PV (LSPV). SLGP is located between left atrial appendage (LAA) and LSPV. B, Left stellate ganglion. C, Superior cardiac branch of the left vagal nerve. D, An example of paroxysmal atrial tachyarrhythmia episode preceded by intrinsic cardiac nerve activity and extrinsic cardiac nerve activity. P-wave morphologies during sinus rhythm (Da) and during paroxysmal atrial tachycardia $(\mathrm{Db})$ were different in magnified pseudo-ECG. LA, left atrium; LOMNA, ligament of Marshall nerve activity; SLGPNA, superior left ganglionated plexi nerve activity; SGNA,

This article is protected by copyright. All rights reserved. 
stellate ganglion nerve activity; VNA, vagal nerve activity. Reprinted from $\mathrm{Choi}^{18}$ et al. with permission.
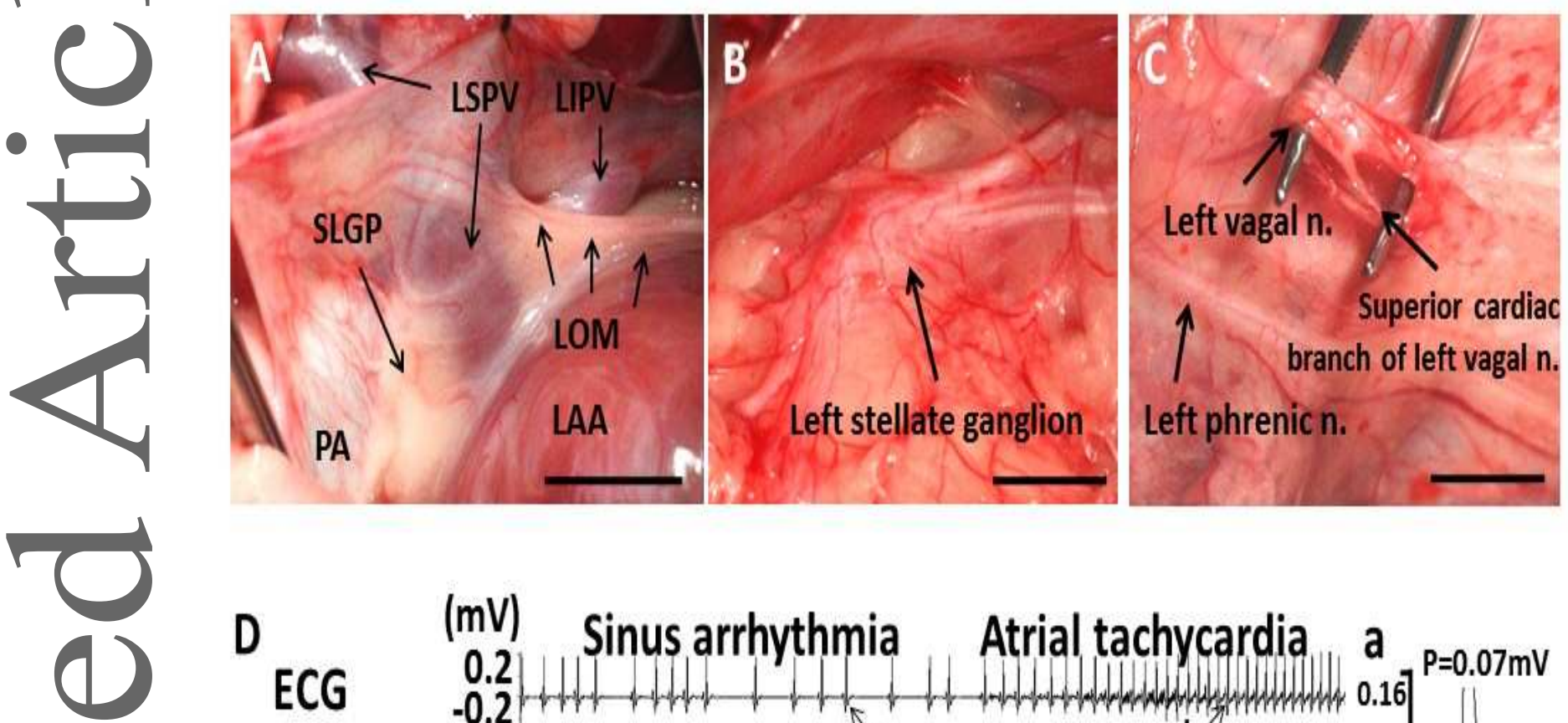

D
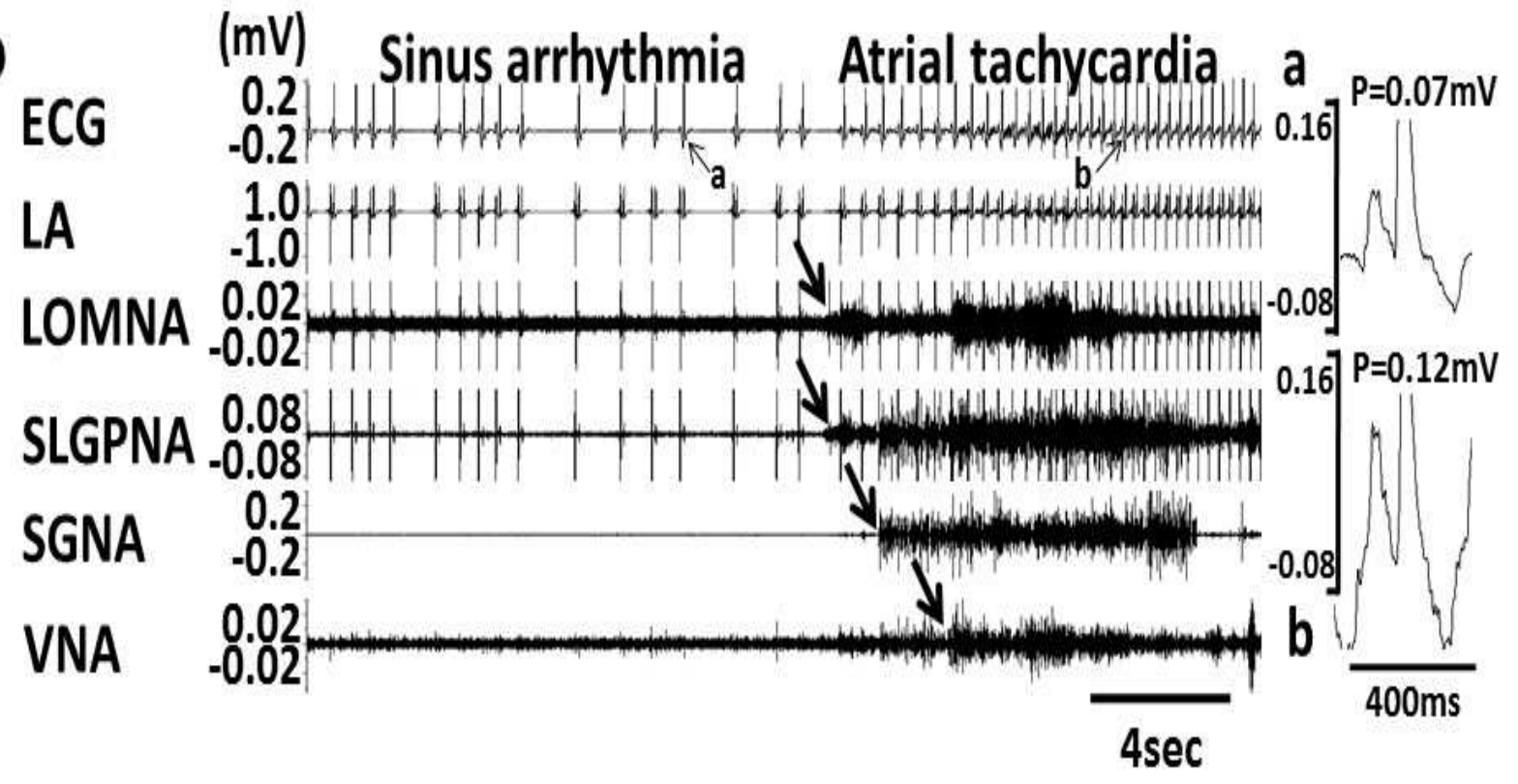

This article is protected by copyright. All rights reserved. 
Figure 2. GP and LOM ablation reduces ventricular rate response to SGNA. A, Graph of statistical dot plot showing that the SGNA-induced ventricular rate acceleration was markedly attenuated by GP ablation compared with the control group. B, An example at baseline shows that a burst of SGNA led to ventricular rate increase from 67 to $117 \mathrm{bpm}$ (74.6\% increment). C, An example after GP ablation shows that a burst of SGNA led to ventricular rate increase from 62 to $73 \mathrm{bpm}$ (17.7\% increment). Reprinted from Zhao ${ }^{40}$ et al. with permission.

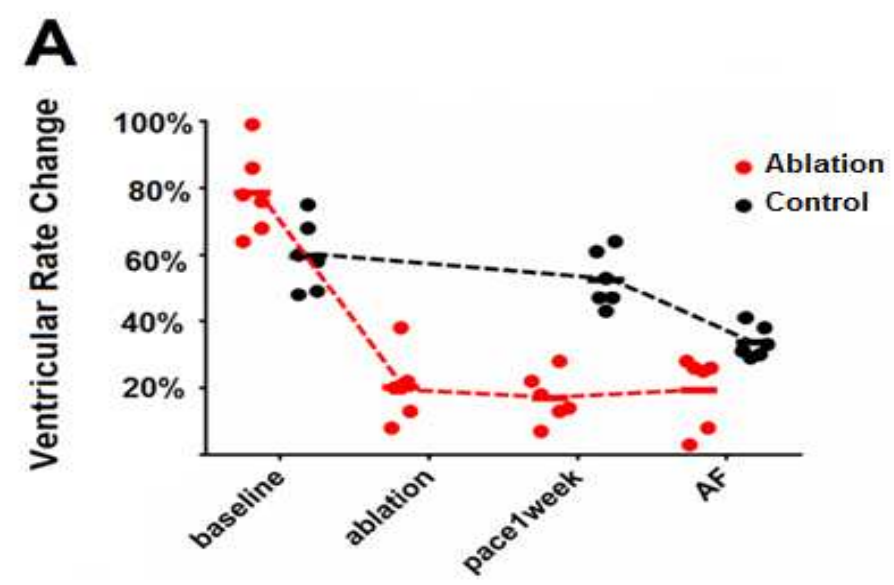

\section{B}

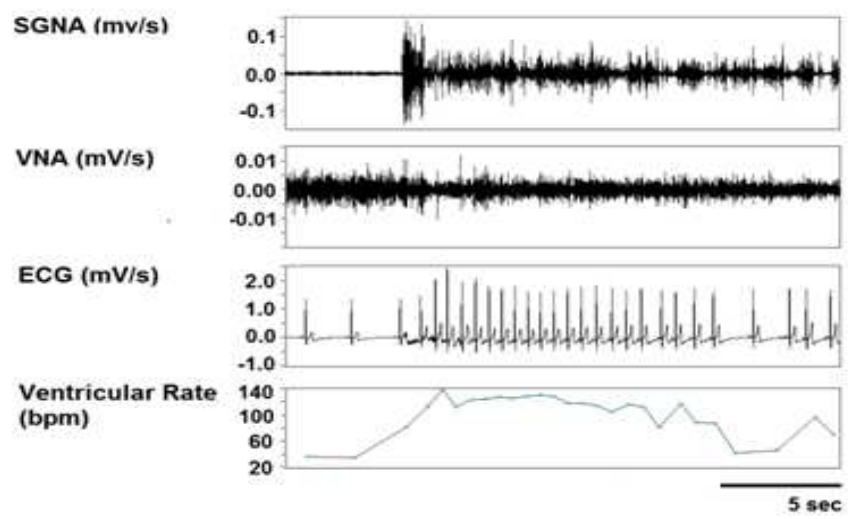

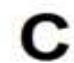

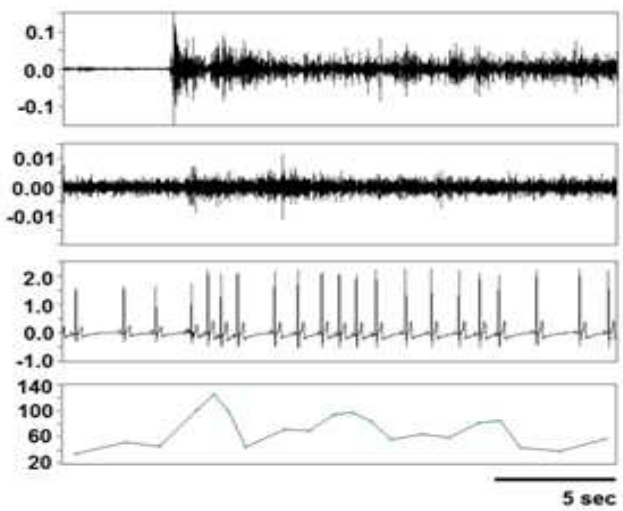

This article is protected by copyright. All rights reserved. 
Table 1. Catheter ablation of the ganglionated plexi for the treatment of atrial fibrillation.

\begin{tabular}{|c|c|c|c|c|c|c|c|c|}
\hline & Study & $\begin{array}{l}\text { Ye } \\
\text { ar }\end{array}$ & $\begin{array}{l}\text { Experim } \\
\text { ent vs. } \\
\text { control } \\
\text { group }\end{array}$ & $\begin{array}{l}\text { Ablatio } \\
\text { n sites }\end{array}$ & $\begin{array}{l}\text { Study } \\
\text { design }\end{array}$ & $\begin{array}{l}\text { Atrial } \\
\text { fibrillati } \\
\text { on type }\end{array}$ & $\begin{array}{l}\text { No. } \\
\text { of } \\
\text { study } \\
\text { patie } \\
\text { nts }\end{array}$ & Outcomes \\
\hline \multirow[b]{2}{*}{$\begin{array}{l}\text { GPA vs } \\
\text { PVAI }\end{array}$} & $\begin{array}{l}\text { Katritsis } \\
\mathrm{DG}^{28}\end{array}$ & $\begin{array}{l}20 \\
08\end{array}$ & $\begin{array}{l}\text { GP vs. } \\
\text { PVI }\end{array}$ & $\begin{array}{l}\text { Endocar } \\
\text { dial }\end{array}$ & CCS & $\begin{array}{l}\text { Paroxys } \\
\text { mal }\end{array}$ & 38 & $\begin{array}{l}\text { AF } \\
\text { recurrence: } \\
74 \% \text { (GP } \\
\text { ablation } \\
\text { group) vs. } \\
37 \% \text { (PV } \\
\text { isolation } \\
\text { group) } \\
\text { (log-rank } \\
\text { test } P= \\
0.017 \text { ) }\end{array}$ \\
\hline & $\begin{array}{l}\text { Mikhaylo } \\
v E^{29}\end{array}$ & $\begin{array}{l}20 \\
11\end{array}$ & $\begin{array}{l}\text { GP vs. } \\
\text { PVI }\end{array}$ & $\begin{array}{l}\text { Endocar } \\
\text { dial }\end{array}$ & $\operatorname{ccs}$ & $\begin{array}{l}\text { Paroxys } \\
\text { mal }\end{array}$ & 70 & $\begin{array}{l}\text { Freedom } \\
\text { from any } \\
\text { atrial } \\
\text { tachyarrhyt } \\
\text { hmia } \\
\text { without } \\
\text { antiarrhyth } \\
\text { mic drugs: } \\
34.3 \% \text { (GP } \\
\text { ablation } \\
\text { group) vs. } \\
65.7 \% \text { (PVI } \\
\text { group) } \\
\text { (log-rank } \\
\text { test } P= \\
0.008 \text { ) }\end{array}$ \\
\hline
\end{tabular}

This article is protected by copyright. All rights reserved. 


\begin{tabular}{|c|c|c|c|c|c|c|c|c|}
\hline \multirow{4}{*}{$\begin{array}{l}\text { GPA+P } \\
\text { VAl vs. } \\
\text { PVAI }\end{array}$} & $\begin{array}{l}\text { Scherlag } \\
\mathrm{BJ}^{33}\end{array}$ & $\begin{array}{l}20 \\
05\end{array}$ & $\begin{array}{l}\text { GP + } \\
\text { PVI vs. } \\
\text { PVI }\end{array}$ & $\begin{array}{l}\text { Endocar } \\
\text { dial }\end{array}$ & Unknown & $\begin{array}{l}\text { Paroxys } \\
\text { mal } \\
\text { or } \\
\text { persiste } \\
\text { nt }\end{array}$ & 60 & $\begin{array}{l}\text { AF-free } \\
\text { survival: } \\
91 \% \text { in GP } \\
+\mathrm{PVI} \\
\text { group vs. } \\
71 \% \text { in PVI } \\
\text { group (no } \\
\text { statistic } \\
\text { compariso } \\
\text { n) }\end{array}$ \\
\hline & $\begin{array}{l}\text { Katritsis } \\
\mathrm{DG}^{31}\end{array}$ & $\begin{array}{l}20 \\
11\end{array}$ & $\begin{array}{l}\text { GP + } \\
\text { PVI vs. } \\
\text { PVI }\end{array}$ & $\begin{array}{l}\text { Endocar } \\
\text { dial }\end{array}$ & RCT & $\begin{array}{l}\text { Paroxys } \\
\text { mal }\end{array}$ & 67 & $\begin{array}{l}\text { Arrhythmia } \\
\text {-free (AF or } \\
\text { AT) } \\
\text { survival: } \\
85.3 \% \text { in } \\
\text { PVI + GP } \\
\text { group vs. } \\
60.6 \% \text { in } \\
\text { PVI group } \\
\text { (log rank } \\
\text { test, } P= \\
0.019 \text { ) }\end{array}$ \\
\hline & $\begin{array}{l}\text { Katritsis } \\
\mathrm{DG}^{32}\end{array}$ & $\begin{array}{l}20 \\
13\end{array}$ & $\begin{array}{l}\text { GP + } \\
\text { PVI vs. } \\
\text { GP vs. } \\
\text { PVI }\end{array}$ & $\begin{array}{l}\text { Endocar } \\
\text { dial }\end{array}$ & RCT & $\begin{array}{l}\text { Paroxys } \\
\text { mal }\end{array}$ & 242 & $\begin{array}{l}\text { AF-free } \\
\text { survival: } \\
74 \% \text { (GP + } \\
\mathrm{PVI} \text { ) vs. } \\
48 \%(\mathrm{GP}) \\
\text { vs. } 56 \% \\
(\mathrm{PVI}) \text { ( log- } \\
\text { rank test } P \\
=0.004)\end{array}$ \\
\hline & Xu FQ ${ }^{34}$ & $\begin{array}{l}20 \\
17\end{array}$ & $\begin{array}{l}\text { GP+re- } \\
\text { PVI vs. } \\
\text { re-PVI }\end{array}$ & $\begin{array}{l}\text { Endocar } \\
\text { dial }\end{array}$ & RCT & $\begin{array}{l}\text { Paroxys } \\
\text { mal } \\
\text { (recurre } \\
\text { d) }\end{array}$ & 123 & $\begin{array}{l}\text { AF-free } \\
\text { survival: } \\
91 \% \text { (GP + } \\
\text { re-PVI) vs. } \\
78 \% \text { (re- } \\
\text { PVI) }(P=\end{array}$ \\
\hline
\end{tabular}

This article is protected by copyright. All rights reserved. 


\begin{tabular}{|c|c|c|c|c|c|c|c|c|}
\hline & & & & & & & & $0.046)$ \\
\hline \multirow{4}{*}{$\begin{array}{l}\text { GPA } \\
\text { without } \\
\text { control } \\
\text { group) }\end{array}$} & $\begin{array}{l}\text { Scanava } \\
\text { cca M }^{35}\end{array}$ & $\begin{array}{l}20 \\
06\end{array}$ & $\begin{array}{l}\text { GP } \\
\text { ablation } \\
\text { or PVI }\end{array}$ & $\begin{array}{l}\text { Epicardi } \\
\text { al } \\
\text { and/or } \\
\text { endocar } \\
\text { dial }\end{array}$ & $\begin{array}{l}\text { Observati } \\
\text { onal } \\
\text { study }\end{array}$ & $\begin{array}{l}\text { Paroxys } \\
\text { mal }\end{array}$ & 10 & $\begin{array}{l}\text { Recurrenc } \\
\text { e in } 5 / 7 \\
\text { patients } \\
\text { who } \\
\text { underwent } \\
\text { denervatio } \\
\mathrm{n}\end{array}$ \\
\hline & Po $S S^{9}$ & $\begin{array}{l}20 \\
09\end{array}$ & $\begin{array}{l}\text { GP + } \\
\text { PVI }\end{array}$ & $\begin{array}{l}\text { Endocar } \\
\text { dial }\end{array}$ & $\begin{array}{l}\text { Observati } \\
\text { onal } \\
\text { study }\end{array}$ & $\begin{array}{l}\text { Paroxys } \\
\text { mal or } \\
\text { persiste } \\
\text { nt }\end{array}$ & 80 & $\begin{array}{l}\text { Free of } \\
\text { symptomati } \\
\text { c AF or AT } \\
\text { after a } \\
\text { single } \\
\text { ablation } \\
\text { procedure: } \\
80 \% \text { at } 12 \\
\text { months } \\
\text { and } 86 \% \text { at } \\
\text { a mean } \\
\text { follow-up of } \\
22 \text { months }\end{array}$ \\
\hline & $\begin{array}{l}\text { Pokusha } \\
\text { lov } E^{27}\end{array}$ & $\begin{array}{l}20 \\
09\end{array}$ & $\begin{array}{l}\text { Selectiv } \\
\text { e GP vs. } \\
\text { anatomi } \\
\text { c GP } \\
\text { ablation }\end{array}$ & $\begin{array}{l}\text { Endocar } \\
\text { dial }\end{array}$ & RCT & $\begin{array}{l}\text { Paroxys } \\
\text { mal }\end{array}$ & 80 & $\begin{array}{l}\text { Free of } \\
\text { symptomati } \\
\text { c } \\
\text { paroxysmal } \\
\text { AF: } 42.5 \% \\
\text { in selective } \\
\text { GP } \\
\text { ablation vs. } \\
77.5 \% \text { in } \\
\text { anatomic } \\
\text { GP } \\
\text { ablation ( } P \\
=0.02)\end{array}$ \\
\hline & $\begin{array}{l}\text { Pokusha } \\
\text { lov } E^{37}\end{array}$ & $\begin{array}{l}20 \\
10\end{array}$ & $\begin{array}{l}\text { Anatomi } \\
\text { c GP }\end{array}$ & $\begin{array}{l}\text { Endocar } \\
\text { dial }\end{array}$ & $\begin{array}{l}\text { Observati } \\
\text { onal }\end{array}$ & $\begin{array}{l}\text { Paroxys } \\
\text { mal }\end{array}$ & 56 & $\begin{array}{l}\text { AF-free } \\
\text { survival at } \\
12 \text { months: }\end{array}$ \\
\hline
\end{tabular}

This article is protected by copyright. All rights reserved. 
